\title{
Postulados inciertos Para UnA PRAXIS ESTÉTICO-POLÍTICA DECONSTRUCTIVA
}

\author{
Fernando Rampéreq'
}

\begin{abstract}
RESUMEN La deconstrucción, precisamente porque no prescribe una estética ni una política, actúa como estrategia de apertura a/de lo diferente y la alteridad, y opera de este modo una propuesta nómada de pensamiento y acción. Algunas categorías que han canalizado la reflexión en estética y política durante siglos, como representación, juicio, interpretación, sentido, firma, secreto, etc. se encuentran con sus impotencias o su lado oscuro o simplemente una nueva lectura "inadecuada" a través de un análisis deconstructivo; este análisis contribuye, así, a pensar de otro modo una estética y una política por venir.
\end{abstract}

PALABRAS CLAVE: Deconstrucción. Estética. Filosofía política. Interpretación. Sentido.

Lo que denomino pensamiento es un gesto polémico con respecto a las interpretaciones consolidadas. (Jacques Derrida)

La deconstrucción, si la hay o si las hay, abre estrategias de creación y lectura de tal modo que en ningún momento resulta sensato establecer algo así como la estética de la decostrucción o la política de la deconstrucción,

1 Fernando Rampérez (Madrid, 1966) es profesor titular de Estética y Teoría de las Artes en la Facultad de Filosofía de la Universidad Complutense de Madrid. Está especializado en estética contemporánea, en las relaciones entre filosofía y literatura, y en pensamiento francés actual. Algunos de sus libros publicados son: A destiempo (Madrid: Biblioteca Nueva, 2009), La quiebra de la representación (Madrid: Dykinson, 2004) y, junto a Paco Vidarte, Filosofías del siglo XX (Madrid: Síntesis, 2005). Forma parte de los grupos de investigación La Europa de la escritura (UCM) y Traducción y deconstrucción (UNED). framperez@filos.ucm.es 
pero sin embargo la praxis de la deconstrucción no deja nunca de constituir una acción a la vez estética y política. Lejos de pobres comentarios que, desde la ignorancia y el impudor más absolutos, hacen coincidir el pensamiento de Jacques Derrida con cierta forma naíf de posmodernismo relativista, al recoger la mejor tradición nietzscheana cada acto deconstructivo opera, al leyendo y escribiendo de otro modo, una cierta subversión con respecto a las convenciones de creación y/o interpretación; y encuentra sentido, un sentido casi terapéutico (pero en cualquier caso liberador, desterritorializante o hipercrítico) en la propia tarea de ir deconstruyendo. Lejos, pues, tanto de cualquier debilidad de pensamiento como de la prepotencia de pensamientos téticos deudores de una metafísica de la presencia, la deconstrucción se hace cargo de y porta sobre sus hombros la fluidez del sentido y la apertura de/a la interpretación, pero lo hace provocando de forma fuerte y consistente esa fluidez y esa apertura mismas como modos estéticos-políticos de ir forzando a su vez la apertura a lo otro en cuanto tal, y de ir resistiendo a la canalización del pensamiento que una posmodernidad de escasas miras comparte con una cierta modernidad parcial y triunfante.

No habrá, pues, ni un corpus teórico ni un conjunto determinable de principios o reglas que puedan cerrarse en lo que se intentaría llamar la estética de la deconstrucción o la política de la deconstrucción, pues una de las estrategias elementales de este proceder está precisamente en cuestionar la completitud y la cerrazón de cualquier repertorio. Y ello es así precisamente porque cualquier cerradura impuesta al pensamiento y a la escritura deberá ser forzada por un ejercicio deconstructivo, realizando en el mismo gesto una emancipación sin fin que no tolera ni siquiera prefigurar sus metas. Contra la corrección lingüística y política, contra la adecuación epistemológica y hermenéutica, una deconstrucción nómada no dejará de dibujar recorridos siempre distintos en vez de caminos facilitados y trillados (literalmente métodos), pues en su ofrecimiento a la diferencia y a la alteridad contiene su raíz nómada, su provocación impropia, su política irreverente, su lectura inadecuada ${ }^{2}$.

2 Peter Sloterdijk, planteándose una vez más en la estela de Heidegger y de Nietzsche a finales del siglo XX la pertinencia del humanismo y entrando en conflicto de este modo con la actitud habermasiana, escribió: "Una lectura adecuada amansa" (en Normas para el parque bumano. Trad. de Teresa Rocha. Madrid: Siruela, 2000). Quizá en esta frase se cifra de modo breve el empeño libertario de otras formas de lectura, sea la genealógica foucaultiana, el esquizoanálisis deleuziano o la propia deconstrucción: otros tantos modos de violentar la prepotencia de la adecuación y de la tesis, así como su servicio a tantas formas de poder. 
Hagamos, pues, lo que no debe hacerse. Y hagámoslo doblemente. No se deben establecer puentes entre lo estético y lo político si, por un lado, se quiere respetar la autonomía de la estética tan arduamente lograda en la Ilustración y si, por otro, pretendemos salvarnos de la estetización fascista de la política contra la que se elevaba Benjamin; pero no vamos a evitar dejarnos seducir por esos espacios sin coordenadas en los cuales la razón roza sus incertidumbres, no vamos a evitarnos el descenso, casi la katabasis, a los infiernos de la decisión política o del juicio estético, y buscar sus paralelismos allí donde la reflexión se topa con la urgencia de pronunciarse, de decidir donde nada es decidible, de resolver lo irresoluble. Se trata de pensar, pues, una relación sin relación entre la filosofía del arte y la filosofía política que deje a ambas indemnes y nos ilumine sobre las vías y el alcance de la deconstrucción derridiana al respecto; que respete la autonomía de las dos esferas y, sin embargo, permita ver en ambas una misma exigencia, o bien una exigencia paralela. Se trata, pues, de pensar ambos espacios, ambas filosofías, más allá del totalitarismo del pensamiento o de la acción o de la lectura o de la creación (si es que no forman un mismo totalitarismo, y lo forman), precisamente allí donde es preciso decidir y porque es preciso.

Y hagámoslo doblemente, lo que no debe hacerse, porque también pediremos explicaciones y principios a quien no consiente principios ni explicaciones (ni orígenes clarificatorios, ni metas justificatorias, ni legitimación de lectura alguna). Tomaremos en esta indagación, de hecho, la perspectiva de la deconstrucción trabajada por Jacques Derrida, para, infieles a su herencia (como no podría ser de otra forma si le somos fieles), transgresores del duelo en que nos obliga a llevarlo en brazos (como de otra forma no podríamos), no hacer caso a sus palabras y extraer de la deconstrucción lo que nunca quiso ofrecernos: principios políticos y argumentos de valoración estética.

Pensemos, pues, desde una doble impostura (cómo pensar de otra forma), y hagámoslo con una inconsecuencia más, deslegitimando todavía más este discurso. Pues no haré un análisis ni exhaustivo ni coherente de la posible traslación de lo estético a lo político, o viceversa (aunque viceversa nunca será lo mismo, pues nunca hay simetría); no hay algo así como una estética de la deconstrucción, y solamente a beneficio de manuales se ha inventado algo así como su política. Si bien la separación de disciplinas y la coherencia nunca han sido valores válidos para Derrida, nunca deja tampoco el autor de ofrecernos una exhaustividad (si no cierta erudición) que pone 
nerviosos a sus detractores. Nosotros, infieles una vez más, tanto a Derrida como a un aparato académico mal entendido, en modo alguno seremos exhaustivos; optaremos por seleccionar palabras y llevarlas de uno a otro sitio, haciendo metáfora, transfiriendo, transgrediendo, trasladando lo intrasladable para hacer que las estatuas de Dédalo cobren movimiento una vez más y se liberen de su sólida atadura ${ }^{3}$.

I.

Quizá la labor estética de la deconstrucción, si es que se puede delimitar así -que no se puede- está en "forcener le subjectile", expresión que toma Derrida al comentar la obra de Artaud: "Entre lo de arriba y lo de abajo hay a la vez un soporte y una superficie, en ocasiones la materia de una pintura $\mathrm{O}$ una escultura, lo que en éstas se distingue de la forma tanto como del sentido y de la representación, lo que no es representable. Su profundidad o su espesor supuestos no dejan ver sino una superficie, la del muro o la madera, también la del papel, del tejido, del tablero. Una especie de piel, agujerada, con poros. [...] Sobre el subjectile deberíamos, sí, deberíamos escribir lo intraducible ${ }^{644}$.

El "subjectile" es en cierta forma sustancia, sujeto, bipokeimenon, subjectum (algo lanzado desde abajo), pero también sujeción, pro-yectil, un lanzamiento, una especie de sujeto sin sujeto, la palabra subjectile es ella misma un subjectile. Intraducible, desde luego. Escapa, por tanto, a la lógica del hilemorfismo tanto como a las oposiciones sustancia/accidente o sujeto/ predicado. Resiste, se resiste a entregarse a dicotomía alguna. Allí donde los pares de conceptos han ido conformando el pensamiento de la metafísica de la presencia y la representación, el subjectile se hace no representable, no presentable, ni apariencia ni fondo, ni fenómeno ni noúmeno, y, sin embargo, aquello sin lo cual no habría obra: su soporte, lo que todo soporta y, sin embargo, a nada se limita o nada limita.

Intraducible, porque es impresentable o irrepresentable. Intraducible, además, porque esa supuesta lengua de la naturalidad, la representación o la comunicación, esa confortable lengua tiempo atrás se ha revelado ya

\footnotetext{
${ }^{3}$ Este análisis no dejará nunca de estar en deuda con el mejor tratado sobre estética y deconstrucción publicado hasta nuestros días, Círculos viciosos de Julián Santos (Madrid: Biblioteca Nueva, 2005).

${ }^{4}$ DERRIDA, J. Forcener le subjectile, en Thévenin y Derrida, Antonin Artaud: dessins et portraits (París: Galimard, 1986, p. 56). La traducción de los textos citados por ediciones francesas es siempre mía.
} 
incómoda, se ha descompuesto con la separación de las palabras y las cosas, y de hecho así quizá la ha mostrado siempre el arte (pero no solamente) cuando nos hemos fijado en su subjectile y nos hemos puesto a la tarea de forcener. Forcener, forzar, violentar, incomodar: otras tantas maneras de desplegar (o dejar que se despliegue) la deconstrucción, ese movimiento que opera en el texto desde siempre y Derrida se ha limitado, según él, a seguir y a dejar ser. Pues "el subjectile resiste. Tiene que resistir. Tan pronto resiste demasiado como no resiste suficientemente. Tiene que resistir para ser por fin tratado en sí mismo y no como el soporte o el servidor de otra cosa, la superficie o el sustrato sometidos de una representación. Ésta debe atravesarse en dirección al subjectile. Pero, a la inversa, el subjectile, pantalla o soporte de la representación, debe ser atravesado por el proyectil. [...] El ni/ni del subjectile (ni sometido, ni insumiso) sitúa por tanto el lugar de una doble coacción : por este motivo se hace irrepresentable ${ }^{\text {c5 }}$.

Estamos ya en el lado de lo intraducible, de lo irrepresentable (si no impresentable), fuera del sueño de la representación y la biunivocidad, ni sometidos ni insumisos a lo que (se) resiste siempre, a lo que siempre resta, y no sabemos, no sabremos nunca, bien qué es, si es que es. No se trata ya de un fondo primordial, de una función estética irreducible, de un secreto más o menos oculto, sino de constatar un desplazamiento del sentido (la différance) a la vez espacial y temporal que genera espacio y tiempo; inscribe, pues, no se inscribe.

Deconstruir es, quizá, tocar el resto, rozar el subjectile y forzar a tomar cuenta del subjectile. Buena parte del pensamiento tradicional ha pretendido comprender sin restos: subsumir sin dejar restos (el crimen perfecto) ni huellas. Sin embargo, podemos pensar que permanecía ciego a los restos, y se contaba, así, la historia de los vencedores, ante cuya victoria cualquier resto quedaba justificado. Frente a ello, la deconstrucción no quiere obviar los restos ni abolir la restancia; se opone conscientemente a subsumir todo, equiparándolo y dando la espalda a lo distinto o lo otro, en la certidumbre, la seguridad, la legitimación y la certeza. Afirmar también significa ordenar; afirmar también significa instalarse, acomodarse; explicar significa también justificar lo injustificable y legitimar lo que debería molestar siempre.

${ }^{5}$ DERRIDA, J. Forcener le subjectile, op. cit., p. 63. 
Y, de este modo, esta operación se hace hipercrítica, ya que no renuncia a cuestionar sus propios supuestos, y nos fuerza por tanto a juzgar sin coartada y a decidir sin la armadura de una lógica binaria o dialéctica.

II.

Esa estrategia, nunca método, que llamamos deconstrucción afecta a supuestos estéticos al menos en dos aspectos, de entrada. Primero, el cuestionamiento de la propia noción de experiencia, deudora de toda una ontoteología: "La experiencia es siempre la relación con una plenitud, sea ésta la simplicidad sensible o la presencia infinita de Dios. Hasta en Hegel y Husserl se podría hacer aparecer, por esta misma razón, la complicidad de determinado sensualismo y de determinada teología. La idea onto-teológica de sensibilidad o de experiencia, la oposición de la pasividad y de la actividad constituyen la homogeneidad profunda, oculta bajo la diversidad de los sistemas metafísicos. [...] El signo es siempre el signo de la caída. La ausencia siempre tiene relación con el alejamiento de Dios. Para escapar a la clausura de este sistema no basta desembarazarse de la hipótesis o de la hipoteca "teológica"،. 6

$\mathrm{Ni}$ actividad ni pasividad valen ya para la experiencia estética, precisamente porque ambas remiten a la misma lógica de la experiencia. Más bien, hay, se da (es gibt Sein) un devenir perpetuo y discontinuo del sentido, tan aprensible como inaprensible, en una tarea de continua (sin continuidad) reescritura. Abrirse a una experiencia así no resulta la menor de la exigencias de una tarea deconstructiva (y quizá la misma que el arte y la literatura han exigido siempre). Una experiencia que, por su parte, va siendo, se va configurando entre los sujetos y más allá de ellos, como la que constituía el relato de transmisión oral cuya añoranza lleva a Walter Benjamin a afirmar que somos pobres en experiencias memorables ${ }^{7}$.

Segundo, cuestionamos el propio concepto de interpretación o creación, ambos sometidos al ideal clásico de la univocidad: ·"La univocidad es la esencia, o mejor, el telos del lenguaje. Ninguna filosofía, en tanto que tal, ha renunciado a este ideal aristotélico. Es la filosofía. Aristóteles reconoce que una palabra puede tener varios sentidos. Es un hecho. Pero este hecho no tiene derecho de lenguaje sino en la medida en que la polisemia ha acabado,

${ }^{6}$ DERRIDA, J. De la gramatología. México: Siglo XXI, 2003, p. 357.

${ }^{7}$ Cf. BENJAMIN, W. El narrador, en Obras, libro II, vol. 2. Trad. de Jorge Navarro. Madrid: Abada, 2009. 
en que las diferentes significaciones son en un número limitado y sobre todo bastante distintas, siendo cada una una e identificable. El lenguaje no es lo que es, lenguaje, más que cuando puede dominar y analizar la polisemia. Sin resto. Una diseminación no dominable no es ni siquiera una polisemia, pertenece a lo de afuera del lenguaje". 8

Hay toda una obligación, una necesidad lógica o filosófica que obliga a la univocidad, y a evitar el resto y las cenizas. Fuera de esa obligación, es decir, fuera del lenguaje, sigue la escritura: la reconfiguración constante de huellas sin original, el recorrido por la diseminación del sentido.

\section{III.}

A partir de aquí, hagamos lo que de ningún modo Derrida aceptaría, o más bien haría: extraer principios para una estética deconstructiva. Y hablemos de principios sin principio; de principios sin final ni finalidad, es decir, sin orden ni jerarquía. Postulados ${ }^{9}$ sin necesidad, estrategias que no dejarán de discutirse a sí mismas impidiendo que en algún momento se hagan obstáculos, piedras que conviertan a la aporía en algo mucho más cerrado todavía. Y que no dejarán de reclamar no ser utilizadas para justificación alguna: es decir, que no eximen de responsabilidad, la responsabilidad del artista, a quien en cada caso juzgue o decida. Principios tan practicables como impracticables, pues.

Primer principio, o primera prevención, la ausencia de sentido propio, la diseminación del sentido, la quiebra de la representación. Hay una disfunción interna, extrañamente interna siempre, que reside incómodamente en la obra de arte, como en todo texto, como en cualquier propuesta de sentido. Y consiste precisamente en que ese sentido nunca está propuesto, o completamente pro-puesto, cerrado, dado sin mácula.

No hay obra sin representación, sin cierta presencia y sin repetición de esa presencia, es decir, sin esa remisión inevitable del signo al significado ausente, o perdido, o convocado, o prometido, y a la vez sin la repetibilidad del signo (sin la cual no es signo, como no lo es sin que cada vez su sentido

\footnotetext{
${ }^{8}$ DERRIDA, J. Márgenes de la filosofía. Madrid: Cátedra, 1989, p. 286.

9 "Digo postulación para apuntar hacia la petición, el deseo, la exigencia imperativa; y digo postulación antes que principio para evitar la principal y poderosa autoridad del primero, de la arkhe o de la presbeia; digo, finalmente, postulación antes que axiomática para evitar la escala comparativa y, por ende, calculable de los valores y de las evaluaciones” (DERRIDA, J. Canallas. Trad. de Peretti. Madrid: Trotta, 2005, p. 170). 
sea diferente, como la misma y diferente y singular cada vez es una firma). Pero nunca en la representación se agota la obra, puesto que ésta nunca presenta sin más: ofrece tanto como se resiste a ofrecer, da más un problema, una dificultad de paso, casi una aporía, que una satisfacción plena y simple. Lejos de la absoluta presencia que quería Ortega, la obra se inscribe en un juego perpetuo de remisiones, de enlaces posibles o imposibles, quebrada ella misma. Y quiebra así ese juego: rompe la aparente continuidad de la línea del tiempo (del sentido, de la historia). La presencia soñada o la presentación primera, en presente, ahora y aquí, en todas partes y siempre, no está nunca dada; resulta más bien un constructo soñado, apolíneo casi, mitología blanca de una restitución de lo que nunca ha sido propio: búsqueda de una propiedad (una posesión, un lugar propio y un sentido propio) a partir de la cual detener el sentido, e imponer una posición o una detención.

Ubicados en el límite, por tanto, entre la representación y la imposible presencia, se trata de pensar ese mismo límite que se resiste a ser conceptualizado, puesto que requiere un pensamiento o una actitud no representativos acerca de lo que excede a la representación, llamémoslo o no subjectile. Y los conceptos mismos tallados para pensarlo son ya representativos, sueñan ya con esa restitución. No es posible ni atenerse a la representación, ni escapar de ella; pero es posible no creérsela, como pide Friedrich Nietzsche al exigir que no olvidemos el carácter metafórico de los conceptos.

Cada obra de arte muestra la imposibilidad de la evidencia, la imposibilidad de clausurar su sentido, cualquier sentido; esa pérdida de fundamento o de suelo que nos sitúa siempre al borde del abismo, y lo hace suspendiendo el juicio tanto como provocándolo, haciendo de cada pronunciamiento un pronunciamiento provisorio y responsable, inacabado tanto como urgente.

Cada juicio estético, pero también cada pronunciamiento político, supone el intento de ubicación, el conato de tomar una plaza y defenderla sabiéndola vulnerable, la colocación en un lugar que nunca será ni propio ni el propio. La búsqueda del lugar propio en cada obra, de cada decisión, nos descoloca, pues, más que ubicarnos; cada pronunciamiento implica un desplazamiento más, un desvío añadido al desvío que reside ya en ese no-lugar o en ese lugar desquiciado de la obra. 
Cada pronunciamiento, cada decisión, cada juicio: nuevas piedras en el camino, pero en modo alguno su clausura, la detención, la esclerosis del sentido. Momentos que habrá a su vez que leer ( $\mathrm{y}$ ahí radica su responsabilidad y su carácter de respuesta).

Ubicados estamos, de esta forma, en el entre: entre la realidad y la ficción, entre las palabras y las cosas. Entre el estatus supuestamente presente y su porvenir o su ausencia, entre lo sensible y lo inteligible, entre lo esperado y la sorpresa, entre el saber y la ignorancia o entre el saber y la locura. Entre lo posible y lo imposible, entre lo que se deja pensar y lo que no se deja. Entre el pronunciamiento y la indecisión: la certidumbre y la incertidumbre, la suficiencia y la insuficencia de la razón y las razones. En un quicio, desquiciados.

Inventando mundo. Haciendo tiempo. Creando y/o leyendo.

Lo absolutamente singular e impredecible, el acontecimiento, resulta ser lo imposible en el marco estable de la representación; cada acontecimiento, por tanto, si lo hay, desestabiliza el orden establecido o esperado o esperable; la pura imposibilidad del acontecimiento muestra la incompletitud de la representación. Hartos ya de obras esperables, de decisiones previsibles, de juicios que no juzgan ni aportan nada, cabe plantearse si hemos cerrado, cobardes y cómplices, la puerta al acontecimiento estético o político.

IV.

La inestabilidad del signo, su desubicación en cuanto se tocan sus supuestos metafísicos (sentido, origen, presencia, significado, referencia, sujeto...) abre en Derrida el pensamiento de la huella. Pues "tanto en el orden del discurso hablado o del discurso escrito, ningún elemento puede funcionar como signo sin remitir a otro elemento que, a su vez, no es(tá) simplemente presente. Ese encadenamiento hace que cada "elemento" -fonema o grafema - se constituya a partir de la huella en él de los otros elementos de la cadena o del sistema. Ese encadenamiento, ese tejido es el texto que sólo se produce en la transformación de otro texto. Nada, ni en los elementos ni en el sistema, es(tá) nunca, en ninguna parte, ni simplemente presente ni ausente. De arriba abajo no hay más que diferencias y huellas de huellas". ${ }^{10}$

${ }^{10}$ DERRIDA, J. Posiciones. Trad. de Arranz. Valencia: Pre-textos, 1976, p. 37. 
La huella supone una remisión sin pausa, inestable; no es una marca que deba ser completada con aquello a que remite; sólo hay huellas de huellas, transferencias de sentido sin origen ni meta, metáforas, representaciones de representaciones que pierden así el carácter de representación. En ese devenir inquieto, un pronunciamiento estético marca una huella más, aunque se quiere pausa, detención, evaluación. Una huella más, y nada más: cada paso un no más allá, pues la huella lleva inscrita una ausencia, una muerte, como cada signo (sigamos a Blanchot).

El campo de la huella es el campo sin límites de una textualidad general: es decir, sin contextos saturables ni horizontes de referencia estamos siempre inmiscuidos en el desplazamiento del sentido. Fuera del universo de la representación (se trata quizá de encontrar categorías estética y políticas más allá de la representación), cada escritura concreta, cada lectura, realiza un recorrido por el libro de arena borgiano (y cada yo se reduce a ese recorrido, a ese subrayado en el libro).

La estética y la filosofía política han intentado siempre reducir esa disfunción interna, esa extrañeza interior de la obra de arte que tantas veces se ha querido entender de modo poco satisfactorio como la inagotabilidad del sentido de la misma, en beneficio de un pensamiento con buen sentido y sentido común, con sentido propio y ombiabarcante. Tantas veces se ha insistido en lo inagotable del texto literario o del cuadro; otras tantas se ha incoado una supuestamente definitiva interpretación. Pero la búsqueda de ese sentido propio siempre perdido y siempre pretendido nos pone en contacto con la cuestión de la propiedad: la coherencia y la cerrazón (o cerradura) del recinto, la delimitación del objeto, del sujeto y del contexto, la deducción a priori de la decisión, la completitud del argumento, la legitimación y la justificación desde un sistema. Como la propiedad semántica, la busca del sentido perdido intenta la apropiación de un espacio asible, hacer propio lo mío, estabilizar o parar el devenir incómodo, esquivar el carácter disolvente del tiempo. Pero la propiedad es siempre inestable, el sentido es siempre de otro. Más que propiedad, hay siempre un ejercicio de reapropiación, un intento de volver a hacer propio (sin origen, sin que lo haya sido jamás, aunque así se pretenda) lo que no es de uno (ni de nadie) (si es que es).

(Reapropiación: por otro nombre, metafísica). 
Si no hay propiedad, no hay tampoco pertenencia. "Pertenecemos (es esto lo que nos arriesgamos a decir aquî) al tiempo de esta mutación, que es precisamente una terrible sacudida en la estructura o la experiencia de la pertenencia. Por tanto, de la propiedad. De la pertenencia y del compartir comunitario" ${ }^{11}$. El desajuste, la quiebra se introduce en el interior de cualquier comunidad, de cualquier conjunto delimitable. La pertenencia es siempre de otros. Y si no hay pertenencia, no hay tampoco pertinencia, la pertinencia es siempre de los otros. Lo pertinente, pero también lo impertinente, es lo que se ajusta a un marco que está ya siempre siendo excedido, imposible de delimitar, perímetro en cuyo recorrido saltamos y tropezamos sin duda. Es la ley de la ley del género ${ }^{12}$. (Una comunidad deconstructiva nunca dejará de escapar a género y de ser discontinua e impertinente).

Para desencanto e incluso desesperación de la hermenéutica, habrá siempre más que una polisemia del sentido, habrá siempre más de una lengua y más de un marco, más de un contexto y más de un horizonte, siempre uno más que impida cerrar cuentas, saldar el período impositivo, imponer una conclusión. El sentido es también siempre otro, o de otro. La alteridad sin fondo está incluida ya en la representación, abriéndola, y en la escritura, y en la lectura. No hay un horizonte estable de sentido; ni horizontes inestables o móviles; el marco tiene siempre un afuera, un afuera más lejano.

Cierto: todo es interpretación. Pero hay siempre más de una. Y las que haya no resultarán nunca equivalentes.

Cada marco se desborda y se revela provisorio; las fronteras no son eternas. El dibujo de los límites, el delimitar(se), es un dibujo que se va haciendo y cuya historia jamás será explicable en un tiempo lineal. No es un dibujo acabado, pero es que ni siquiera es coherente. Queda siempre un resto y una resistencia, una restancia, que impide cerrar el cuadro, siquiera sea a beneficio de inventario; el inventario mismo está aquejado de mal de archivo; el inventario mismo es autoinmune. La mano que delimita o dibuja el perímetro experimenta quizá de continuo un empuje, un desplazamiento; nos salimos del borde, no cerramos el círculo.

Y la lectura, así, queda liberada del horizonte del sentido, del orden del sentido, y enganchada a la cuestión del estilo y del relato infinito. Libera y se

\footnotetext{
${ }_{11}$ DERRIDA, J. Políticas de la amistad. trad. de Vidarte y Peñalver. Madrid: Trotta, 1998, p. 98.

${ }^{12}$ Cf. DERRIDA, J. Parages. París: Galilée, 1986. 
libera del orden del sentido, del sentido del ser o de la verdad del sentido del ser, del orden de la producción o de la presencia o del presente; se desencadena de este modo la cuestión del estilo como cuestión de la escritura, con una operación que va más allá de cualquier sentido, cualquier significado, toda representación o todo contenido ${ }^{13}$.

Se trata, pues, de la representación impresentable: de la impresentable presentación de una obra de arte, de un texto, pero también de la impresentable representación política, es decir, de esa remisión de voluntades no unívocas, traicioneras siempre, o de la falacia del representante. Donde sólo hay un sujeto él mismo quebrado, un sujeto que aloja en su interior no delimitable una cierta disfunción, ninguna ley garantizará la fidelidad del representante. Cualquier representante es infiel: es la ley; hay, quizá, que pensar una democracia sin representación. La ley misma es la ley de la infidelidad a la representación, la ley de discontinuidad de voluntades, de remisiones sin fondo ni horizontes abarcables. «La ley misma no es ni presentable ni representable»: "El sujeto es aquello que puede o cree poder darse representaciones, disponerlas y disponer de ellas. Cuando digo «darse representaciones», podría decir también, cambiando apenas de contexto, darse representantes (por ejemplo políticos) o incluso, volveré sobre ello, darse a sí mismo en representación o como representante. Esta iniciativa posicional -que estará siempre en relación con un cierto concepto muy determinado de la libertad- la vemos marcada en el Stellen de Vorstellen. [...] Cualquiera que sea la necesidad de esa cuestión acerca de la relación entre la ley y las huellas (las remisiones de huellas, las remisiones como huellas), tal cuestión se sofoca quizá cuando se cesa de representarse la ley, de aprehender la ley misma bajo la especie de lo representable. Quizá la ley misma desborda toda representación, quizá no está jamás ante nosotros como aquello que se sitúa en una figura o se compone una figura. (El guardián de la ley y el hombre del campo sólo están «ante la ley», Vor dem Gesetz, dice el título de Kafka, al precio de no llegar jamás a verla, de no poder llegar jamás a ella. La ley no es ni presentable ni representable y la «entrada» en ella, según una orden que el hombre del campo interioriza y se da, se difiere hasta la muerte.) A menudo se ha pensado en la ley como en aquello mismo que pone, se pone y se junta en la composición (thesis, Gesetz, dicho de otro modo, lo que rige el orden de la representación) y la autonomía supone siempre la representación, como la tematización, el hacerse-tema. Pero la ley misma no llega quizá, no

${ }^{13}$ Cf. DERRIDA, J. Espolones, los estilos de Nietssche. Trad. de Arranz. Valencia: Pre-textos, 1981. 
nos llega, sino transgrediendo la figura de toda representación posible. Cosa difícil de concebir, como es difícil de concebir cualquier cosa que esté más allá de la representación, pero que obliga quizás a pensar completamente de otro modo". ${ }^{14}$

\section{V.}

Segunda cuestión o segundo principio: Cada firma (como cada decisión, cada juicio o cada promesa) supone una marca en la "errancia espectral de las palabras ${ }^{15}$ ". Ese espacio completo y coherente soñado por una metafísica clásica excluía la firma y la responsabilidad de la decisión; o más bien pretendía excluirlas, postulando una verdad impersonal y un sentido de todos y de nadie, un sentido para todos y para nadie. Pero la firma será siempre ineludible, cada interpretación será una autobiografía, tan responsable e irresponsable, pues, como la biografía misma o como la vida. Por eso, "llamarás poema de ahora en adelante a una cierta pasión de la marca singular, la firma que repite su dispersión, cada vez más allá del logos, anhumana, doméstica a penas, no reapropiable en la familia del sujeto"16.

La firma va junto al acontecer singular de la obra, irreducible a contextos (incluso a biografías, caracteres socio-culturales, estilos...: más bien hace biografía, hace estilo, hace cultura...). Nada hay fuera de texto, de hecho. Pero es una singularidad tan repetible como irrepetible: es la posibilidad de la repetición (o no) lo que hace que la firma sea firma. Es la posibilidad de la repetición lo que hace que la obra sea obra (la repetición de la obra tanto como la repetición del espectador en masa, como de hecho le importaba a Benjamin), que se presente, que se represente, que dé y escatime su sentido. La firma es quizá la única forma que queda de referirse al sujeto: iterabilidad singular sin sustancia de la que sólo queda el nombre (si queda, si se cita, si con él nos citamos): las bellas artes son siempre del marco y de la firma.

La firma busca su sitio, pero se repite porque no encuentra nunca su lugar propio, no descansa nunca, nunca se queda cómoda, nunca queda conforme. Como cada decisión, como cada obra. Se hace sitio, intenta hacerse

\footnotetext{
${ }^{14}$ DERRIDA, J. Envío. In: La desconstrucción en las fronteras de la filosofía. Trad. de Peñalver Barcelona: Paidós, 1996.

${ }^{15}$ Idem. Schibboleth. Trad. de Pérez de Tudela. Madrid: Arena, 2002 , p. 96.

${ }^{16}$ Idem. Che cos’é la poesia? In: ___ Points de suspension. París: Galilée, 1992, p. 307. 
sitio desplazando, trasladando, transfiriendo, metaforizando. Se lleva en vilo. Te lleva en brazos. Destinerrancia. No encuentra su sitio. Y, sin embargo, sólo es firma si ocupa un lugar determinado, el lugar de la firma. Quizá el movimiento de la mano que busca ese lugar va haciendo la escritura o la obra o la biografía.

Y en la medida en que no encuentra su sitio, no es deducible de programa alguno: "No hay poema sin accidente, no hay poema que no se abra como una herida, mas que no sea hiriente también. Llamarás poema a un encantamiento silencioso, a la herida áfona que, de ti, deseo aprender de memoria" ${ }^{\prime 17}$. Incalculable, es original en ese sentido, imprevisible e impredecible: ve lo que no cabe ver, dice lo no decible, prevé lo imprevisto. Acontece y firma. Desmedida, resiste a la conceptualización. Deseo insaturable, no neutralizable.

Cada firma merece respeto. Es lo que merece respeto. Cada singularidad, cada paso de una biografía: una apuesta siempre, una promesa que abre hacia un mundo por venir. Es su inseguridad lo que la hace responsable y es la incertidumbre de su trazo lo que la hace merecedora de respeto. (Presente y lejana a la vez, titubeante y comprometida, quizá en ella radica el aura de la obra, exigiendo un respeto y un ritual que nos sustrae a masificación alguna). (La firma es lo que escapa a la masificación; es una forma de individualización, o la soledad incluso, transida como está de ausencia y muerte).

VI.

Tercero: prometamos (hipócritas o soñadores) decirlo todo.

Cada palabra (cada gesto, cada trazo, cada pigmento) es una promesa de sentido o de verdad, una toma de postura, un compromiso, una afirmación performativa (heme aquí, esto digo, esto hago) y no constatativa ni tética, una testificación, un pacto incierto con el porvenir, una conjuración imposible del porvenir. Cada palabra es una cita: una nota a pie de página, la repetición de algo ya dicho; pero también una cita con el otro o con lo otro, una forma de quedar para después, el compromiso de un encuentro sin presente ni presencia que siempre quedará diferido. Estamos a cada paso en literatura y filosofía citándonos: repitiéndonos, y quedando para después. Estamos a cada paso en democracia repitiéndonos, universalizando e igualando, y quedando para después: abriéndonos a un futuro incierto en el cual quizá volvamos a encontrarnos o volvamos a citarnos. Si es que no nos esperamos (en) la muerte.

${ }_{17}$ DERRIDA, J. Che cos'é la poesia? In: ___ Points de suspension. París: Galilée, 1992, p. 307. 
Cada palabra dice, por tanto: espero, esto espero; o bien: te espero. Testifica, atestigua: espero. La literatura, o la democracia, es una agenda: anotaciones de lo por hacer, de las citas por cumplir, de lo que aún nos falta. Enumeración del deseo, cita, repetición casi compulsiva del deseo. Casi credo.

Pero cada cita presupone también la posibilidad de la ocultación, la apertura al espacio no público, o incluso la infidelidad: citar en secreto.

Como una cita sin nota al pie, una cita encubierta que reta al lector o bien directamente le engaña; una deslealtad hacia el citado y una mentira hacia el que lee. O bien ignorancia del escribiente. $U$ olvido. $U$ homenaje encubierto. Una cita secreta.

Pero también una cita en secreto, el compromiso doble de encontrarse fuera del presente y sin aparición pública. Citarse para un encuentro que quizá uno mismo ignora, cita secreta para los que se citan y, citándose, están en el secreto. Puesto que no hay uno mismo, puesto que uno no es nunca el mismo, quizá toda cita sea pues secreta, ignorada, y de ahí la apertura inevitable al otro, a lo otro, o al porvenir.

(Nos) citamos en secreto, por tanto, porque no nos haremos nunca suficientemente cargo de nuestro deseo o nuestro credo.

Cada cita en secreto supone la promesa, la apuesta por una comunidad sin pertenencia. Nunca sabemos exactamente con quién estamos citados, a quién citamos, quién cita a quién.

La cita secreta puede ser también una cita no explícita, no firmada o confirmada: la palabra no pronunciada o no dicha. Lo político está construido sobre lo no dicho: sobre palabras no pronunciadas, sobre citas cuya referencia no ha sido precisada, sobre citas secretas, citas no confirmadas o incluso incumplibles. Un contrato cuyas cláusulas se desconocen (y la ignorancia de la ley no exime de su cumplimiento). Un contrato o una cita siempre desajustada, que nunca llega a tiempo, y desequilibrada. No inconmensurable: desequilibrada. La democracia, como la literatura, es un conjunto de citas no saturable, desmesurado (pero no necesariamente inconmensurable), no cumplible. O sí.

El secreto es, pues, algo más (u otra cosa) que ese ámbito de sentido inagotable, esa resistencia que lo estético siempre ha querido subrayar con respecto a cualquier interpretación o cualquier enjuiciamiento. No 
es simplemente el carácter inagotable de la obra, paralelo a la consabida insatisfacción pseudoromántica. Es $\left(\mathrm{si}^{\mathrm{es}}{ }^{18}\right.$ ) el desajuste estructural de la representación, y del tiempo, y de la promesa, y de la cita. Es la posibilidad de no quedar nunca, de que nada quede nunca, de que nadie quede nunca, de que la cita no se presente a tiempo, o de que la cita secreta me sea denunciada, desvelada, es decir, de que la infidelidad se haga pública, o de que se haga pública mi cita secreta contigo, con vosotros.

El secreto desmonta la oposición entre el velamiento y el desvelamiento del sentido. Luz soñada, iluminación deseada, ninguna obra satisfará ese anhelo de plenitud; pero tampoco lo contrario. La tensión hacia la verdad, la promesa de verdad, será siempre previa (o estará en otro momento o en otro lado) a la determinación de la verdad como adecuación o como aletheia. La obra de arte no desvela: vela. Permanece en vela para velar cada muerte, se hace heredera de cada muerte, está constituida por pasado y promesa. Testifica: esto queda. $\mathrm{O}$ más bien esto quiere quedar.

(Secreto o muerte: lo que todavía queda por decir).

La palabra (cada pincelada, cada fotograma...): exigencia de sentido. Pero exigencia siempre incumplida (le pas an déla $a^{19}$ ). Promesa, pues.

En Passions, Derrida identifica la literatura y la democracia: ambas consisten en la posibilidad de decirlo todo. Pero a renglón seguido subraya de la literatura el hecho de que resulte el lugar del secreto: "Si, sin amar la literatura en general y por sí misma, amo algo en ella que desde luego no se reduce a alguna cualidad estética ni a fuente alguna de goce formal, eso estaría en el lugar del secreto. En el lugar de un secreto absoluto. Ahí estaría la pasión. No hay pasión sin secreto, este secreto, pero tampoco hay secreto sin esta pasión. En el lugar del secreto: allí donde sin embargo todo está dicho, y donde el resto no es nada, nada que reste, nada más que el resto, ni siquiera literatura". ${ }^{20}$

Pensemos que también la democracia es el lugar del secreto, ese mismo lugar donde todo es decible. Donde todo es decible, ha lugar al secreto; sólo

\footnotetext{
18 "No hay secreto como tal, lo deniego. Y esto es lo que confío en secreto a cualquiera que se alíe conmigo. Este es el secreto de la alianza". DERRIDA, J. Cómo no hablar..., Barcelona: Anthropos, 1997, p. 12.

${ }^{19}$ BLANCHOT, M. El paso (no) más allá. Trad. de Peretti. Barcelona: Paidós, 1994. Cada palabra da un paso y niega el paso, niega el más allá del paso a la vez que lo da.

${ }^{20}$ DERRIDA, J. Passions. París: Galilée, 1993, p. 64.
} 
tiene sentido el secreto si todo se puede decir; sólo puede todo decirse si es posible también callar, si queda siempre algo por decir, si la respuesta puede ser una no-respuesta, o el silencio. En eso consiste la literatura: "hay en la literatura, en el secreto ejemplar de la literatura, una oportunidad de decir todo sin tocar el secreto“21. Y en eso consiste la democracia: en que quede algo por decir, y queramos decirlo (un paso más allá de la muerte).

\section{VII.}

Cuarto principio: deber de memoria.

Cada obra de arte está hecha de memoria. Una memoria en modo alguno propia: ni memoria de sí, ni memoria encontrada dentro de sí, ni memoria de lo propio, ya sea de sí mismo o de cualquier tipo de propiedad. Memoria siempre impropia, por tanto: inapropiable o memoria del otro o de lo otro. O del otro que uno mismo es. Memoria que nunca da lugar a un repertorio finito ni continuo de recuerdos, pero por lo mismo tampoco infinito; en cualquier caso, del todo inapropiable; inapropiable del todo.

Memoria y tradición se entienden aquí como quiere entenderlas Benjamin: un pasado discontinuo y todavía presente del cual hacerse cargo, y de cuya herencia habrá de surgir la promesa de un porvenir distinto. (No habría deconstrucción sin ese bucle del tiempo que Benjamin forzó: la relectura continua en presente de un pasado discontinuo que nos dice en cierta medida qué hacemos aquí y en este momento, y a partir de la cual nos com-prometemos con un porvenir realmente por venir).

La memoria es ya un relato; el testigo establece sobre ella su propia lógica. Un repertorio desubicado, ni inteligible ni sensible, inaccesible a cualquier anamnesis que se quiera completa, que pretenda encontrar dentro de sí lo buscado, el sentido perdido o la decisión adecuada.

Cada obra, pues, establece una memoria en calidad de testigo, pero de testigo dubitativo y desmemoriado que transgrede o altera el contenido tanto como lo transmite. Testigo que hereda en un duelo ${ }^{22}$ imposible, y se convierte en infiel a la herencia en la misma medida en que se hace cargo de

${ }^{21}$ Ibidem, p. 67

22 "No hay política - diremos de una forma económica, elíptica y, por consiguiente, dogmática sin organización del espacio y del tiempo del duelo, sin topolitología de la sepultura, sin relación anamnésica y temática con el espíritu como (re)aparecido, sin hospitalidad abierta al huésped como 
ella. Testigo inseguro de una memoria incoherente. Pero testigo que atestigua que la versión oficial de la historia, o la lectura adecuada y mansa de la obra, no merece crédito ni respeto.

Y, así, la memoria se hace deber ${ }^{23}$ : deber de memoria. Herencia no solicitada, nos (a)coge a contratiempo, nos descoloca con una llamada ante la que estamos siempre ya de antemano respondiendo. Ya antes en duelo, enduelados y endeudados sin fondo y al infinito: enduelados con la muerte de otros, de los que han muerto y de los que van a morir (de los que vamos a morir), dejando deudas impagadas. Es la única forma no totalitaria del compromiso político; la única forma de compromiso estético que respeta la autonomía del arte. Autonomía, por tanto, pero nunca desinterés.

Deber de memoria, pero nunca memoria sólo por deber (aus Pflicht): no devaluemos el deber tanto.

Pues no hay arte interesado ni desinteresado: hay arte comprometido siempre por una herencia no pedida, un arte tan autónomo como testificante; testigo siempre, en un testimonio inaprensible, quebrado en su propia palabra, notario de una promesa insatisfecha, testigo de un pasado releído.

Arte testigo, arte que da el testigo.

ghost al que nosotros mantenemos como rehén tanto como él nos mantiene a nosotros en calidad de tales” (DERRIDA, J. Aporías. Trad. de Peretti. Barcelona: Paidós, 1998, p. 103).

23 "Esta responsabilidad ante la memoria es una responsabilidad ante el concepto mismo de responsabilidad que regula la justicia y lo ajustado de nuestros comportamientos, de nuestras decisiones teóricas, prácticas, ético-políticas. Este concepto de responsabilidad es inseparable de toda una red de conceptos conexos (propiedad, intencionalidad, voluntad, libertad, conciencia, conciencia de sí, sujeto, yo persona, comunidad, decisión, etc.). [...] Pero en el momento en que el crédito de un axioma es suspendido por la deconstrucción, en ese momento estructuralmente necesario, siempre se puede creer que no hay lugar para la justicia ; ni para la justicia misma ni para el interés teórico que se dirige a los problemas de la justicia. Es éste un momento de suspensión, ese tiempo de la epokhé sin el cual no habría deconstrucción posible. No es un simple momento: su posibilidad debe permanecer estructuralmente presente en el ejercicio de toda responsabilidad en la medida en que esta última no se abandone a un sueño dogmático y no reniegue de ella misma. Por ello, ese momento se desborda a sí mismo. [...] Ese momento de suspense angustiante abre también el intervalo o el espaciamiento en el que las transformaciones y hasta las revoluciones jurídico-políticas tienen lugar. Sólo puede estar motivado, sólo puede encontrar su movimiento y su impulso (un impulso que no puede ser suspendido) en la exigencia de un incremento o de un suplemento de justicia y, por tanto, en la experiencia de una inadecuación o de una incalculable desproporción. Ya que, en definitiva, ¿dónde podría encontrar la deconstrucción su fuerza, su movimiento o su motivación sino en esa apelación siempre insatisfecha más allá de las determinaciones dadas y de lo que llamamos en determinados contextos la justicia, la posibilidad de la justicia?” (DERRIDA, J. Fuerza de ley. Trad. de Barberá y Peñalver. Madrid: Tecnos, 1997, p.47-48). 
La huella, el signo, requieren memoria. Y cada actualización provisoria del sentido resulta un testimonio, un compromiso, una promesa de sentido.

Una memoria nunca es completa, sistemática, sistémica. El testimonio se sabe parcial e interesado, prometido y comprometido. Firmado. Confirmado. Es el testimonio de una vida vivida, el testimonio que ha conformado una vida.

Y el testigo se sabe mortal: testifica, de entrada, que su testimonio puede interrumpirse en cualquier momento, que en cualquier momento puede no haber ya testigo. La memoria, pues, es un duelo probable de sí, el testigo vela también su propia muerte como la de cualquier otro; Gelman dice: "de todos modos, yo soy otro".

El testigo hace relato, un relato dotado de su propia lógica, la del testimonio; un relato situado más allá de la verdad o la ficción, que transgrede la veracidad y va más allá de ella para convertirse en memoria. La realidad del relato testificado es virtual, espectral, ni cierta ni falsa, ni aparecida ni escondida, reaparecida en todo caso, rememorada, revivida o vivida así. Memoria convertida en leyenda, memoria que ha de ser leída, recontada, transmitida: e ir haciendo de ese modo un relato memorable para que tengamos experiencia de él y dejemos de ser pobres de experiencia.

La memoria lo es de lo otro o de otro: nunca me recuerdo a mí mismo, al recordarme me recuerdo otro y me sé otro, es otro el recordado y otro el que recuerda. El relato nunca me pertenece.

La memoria, pues, en su relato, da lugar a un espaciamiento que enlaza con lo otro. La alteridad y el recuerdo forman la materia prima de lo estético o lo político.

\section{VIII.}

Quinto: Ninguna decisión a tiempo, a tiempo ningún juicio.

Todo acontecimiento implica un desajuste. El presente es una interrupción. La decisión es una interrupción del juego de remisiones en 
eterno retorno. Se da, pues, siempre fuera de tiempo ${ }^{24}$. Ninguna decisión a tiempo ${ }^{25}$, pues; a tiempo ningún juicio.

El tiempo se ha construido siempre en paralelo a la presencia. Continuum tiempo-espacio: la simultaneidad. Es ahí, pues, donde se introduce la différance, el espaciamiento que da tiempo, la temporalidad que va abriendo sitio, dando lugar, haciendo tiempo, ambos procesos en una mala armonía. Disimétricos.

(Vivimos, quizá, para hacer tiempo. Morimos, quizá, para hacer sitio).

El espacio/tiempo concebido como marco absoluto configura la escena posible, la escena de lo posible, el escenario de la representación. Prevé cualquier aparición, cualquier manifestación, cualquier sensibilidad posible y, de esta forma, cualquier estética. Y así las neutraliza. Pero no: el fantasma, la aparición incontrolada, viene a colarse entre estos supuestos, viene a cuestionar ese continumm. Viene a contratiempo y sin presencia: nunca se sabe si es o está o ni es, nunca se sabe si está ahora. Como la realidad espectral de los media y de la red. O como el arte cuestiona espacio y tiempo.

Ni fenómeno ni noúmeno, ni ausente ni presente, ni tuyo ni mío, ni vivo ni muerto: la red, el fantasma, la memoria, el sentido de la obra de

\footnotetext{
24 "No puede haber don sino en el instante en que una fractura haya tenido lugar en el círculo: en el instante en que toda circulación haya sido interrumpida y a condición de ese instante. Y, además, dicho instante de fractura (del círculo temporal) ya no debería pertenecer al tiempo. Por eso hemos dicho "a condición de ese instante". Esta condición concierne al tiempo pero no le pertenece, no depende de él, mas no por ello es ésta más lógica que cronológica. No habría don sino en el instante en que el instante paradójico (en el sentido en que Kierkegaard dice que el instante paradójico de la decisión es la locura) desgarra el tiempo. En este sentido, el tiempo, el "presente" del don ya no se puede pensar como un ahora, a saber, como un presente encadenado a la síntesis temporal". "No hay problemática del don sino a partir de una problemática consecuente de la huella y del texto. Jamás puede haberla a partir de una metafísica del presente, ni siquiera del signo, del significante, del significado o del valor" (DERRIDA, J. Dar (el) tiempo. Trad. de Peretti. Barcelona: Paidós, 1995, p. 19; 101).

25 "La decisión produce acontecimiento, ciertamente, pero neutraliza también ese sobrevenir que debe sorprender tanto la libertad como la voluntad de todo sujeto, que debe sorprender en una palabra la subjetividad misma del sujeto, afectarlo allí donde el sujeto está expuesto [...]. Sin duda la subjetividad de un sujeto, ya, no decide nunca sobre nada: su identidad consigo y su permanencia calculable hacen de toda decisión un accidente que deja al sujeto indiferente. Una teoría del sujeto es incapaz de dar cuenta de la menor decisión. [...] La decisión pasiva, condición del acontecimiento, es siempre en mí, estructuralmente, otra decisión, una decisión desgarradora como decisión del otro. Del otro absoluto en mí, del otro como lo absoluto que decide de mí en mí. Absolutamente singular en principio, según su concepto más tradicional, la decisión no es sólo siempre excepcional, hace excepción de mí. En mí. Decido, me decido, y soberanamente, esto querría decir: lo otro de mí, el otro-yo como otro y otro de mí, hace o hago excepción de lo mismo. Norma supuesta de toda decisión, esta excepción normal no exonera de ninguna responsabilidad” (DERRIDA, J. Políticas de la amistad, op. cit., p. 86-87).
} 
arte; y también la irrealidad del mundo de la comunicación o incluso de lo comunicado.

El espectro es el extranjero, el tercero, el testigo, el que te saca de tus casillas porque te quita sitio, pide que se le haga sitio. El espectro desestabiliza el orden de lo esperado o lo esperable, las coordenadas de la metafísica tradicional pero también de una estética de la sensibilidad. Asedia la cerrazón de cada concepto, y es ahí donde adquiere relevancia política: no sólo porque lo político trabaje con esa esfera pública o mediática que puede considerarse espectral, sino también porque se introduce en el interior de cada decisión o cada programa para hacerlo siempre inadecuado, desplazado, intemporal, ya que "ocurre que la inadecuación al concepto forma parte del concepto mismo. Esta inadecuación consigo mismo del concepto se manifiesta por excelencia en el orden de lo político o de la práctica política, a no ser que este orden, o más bien su posibilidad, sitúe el lugar mismo, el fenómeno o la "razón" de una inadecuación consigo de todo concepto: el concepto de la disyunción como ser-conceptual del concepto. De ahí se sigue que incluso lo que se llama una política, una política ideal, un enfoque regulador y programático, incluso una idea de la política en general, no podrían establecer(se) (sobre la base de) un tal "concepto de lo político"", 26

El desquiciamiento que abre el programa a lo que no se deja deglutir, que obliga a mirar siempre más allá (que no a otro lado), también quizá más allá del diálogo. Desquiciamiento que disuelve la coherencia del concepto de lo político mismo. La política, siempre fuera de tiempo, se hace así tarea de inadecuación y temporalización: resitúa, da tiempo, se abre a cada nacimiento y cada muerte. Allí donde tantas políticas marcan el camino y se creen sabedoras de la meta, del origen y del porvenir, debería quizá la democracia hacerse una grieta dentro de sí misma para evitar cualquier planteamiento totalizador, totalizante o totalitario, hendirse para hacerse hospitalaria a una alteridad no prefigurada y un porvenir incierto. Por ese espacio de incertidumbre, y solamente por él, cabe la libertad de un ciudadano.

IX.

Sexto: principio de razón insuficiente.

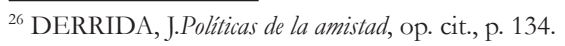


Nada es decisorio, ni decisivo. La razón nunca es suficiente, pero la realidad tampoco lo es. Hay siempre más de una lengua, más de una interpretación, más de un motivo. La justificación, la legitimación nunca está cerrada. Afortunadamente no hay justificación. Y el código de seguridad del cierre no es descifrable.

Puesto que nada está en su lugar propio, puesto que no hay propiedad ni pertenencia ni lugar adecuado, cualquier jerarquía es cuestionable (principio de anarquía). En el archivo, en todas las fichas firmadas, consignadas, repetidas y repetibles, habita la pulsión de muerte; y ningún archivo es (afortunadamente) completo. "Ahora bien, esta amenaza es in-finita, arrastra la lógica de la finitud y los simples límites fácticos, la estética transcendental, podría decirse, las condiciones espacio-temporales de la conservación. Digamos más bien que abusa de ello. Un abuso así abre la dimensión ético-política del problema. No hay un mal de archivo, un límite o un sufrimiento de la memoria entre otros: al implicar lo in-finito, el mal de archivo está rozando el mal radical". ${ }^{27}$

El archivo pretende hacer homenaje al acontecimiento explicándolo, dándole sitio, momificándolo y haciéndolo patrimonio de una memoria exhaustiva y completa. Pero a la vez lo conjura, lo estandariza, lo clasifica y mata. Pulsión de muerte en el afán archivador; pero pulsión de muerte en el archivo mismo: genera reacciones autoinmunes que acaban por apolillar el archivo.

(Y está lo que defeca el archivo: su expurgo.)

Pero todo archivo es incompleto: "ningún archivo sin afuera". Ninguna memoria es exhaustiva. Sólo una razón que se sabe insuficiente está en guardia ante sus prepotencias y ante sus impotencias. El círculo nunca está cerrado, ninguna decisión es adecuada, a tiempo ningún juicio, ningún juicio a tiempo, justo adecuado. Sólo una razón que se sabe tan suficiente como insuficiente acepta su responsabilidad y sigue razonando: no reduce todo a la aplicación de un programa: se sabe insuficiente si decide por deber, solamente por deber.

Ninguna decisión es tal sin la pausa, el silencio de una indecisión, la sospecha de una insuficiencia: "La ética prescribe una política y un derecho, esta dependencia y la dirección de esa derivación incondicional son tan irreversibles como incondicionales. Pero el contenido político o jurídico de esta manera asignado permanece, por el contrario, indeterminado, siempre por

${ }^{27}$ DERRIDA, J. Mal de archivo. Trad. de Vidarte. Madrid: Trotta, 1997, p. 27. 
determinar, más allá del saber y de cualquier presentación, de todo concepto y de toda intuición posibles, singularmente, en la palabra y la responsabilidad asumidas por cada cual, en cada situación, y a partir de un análisis cada vez único --único e infinito, único pero a priori expuesto a la substitución, única y, sin embargo, general, interminable no obstante la urgencia de la decisión. $\mathrm{Y}$ es que el análisis de un contexto y de las motivaciones políticas nunca tiene fin, dado que incluye en su cálculo un pasado y un porvenir sin límite. Como siempre, la decisión permanece heterogénea al cálculo, al saber, a la ciencia y a la conciencia que, empero, la condicionan. El silencio del que estamos hablando, el silencio hacia el que alargamos el oído, es el entretiempo elemental y decisivo, el entretiempo instantáneo de la decisión, el entretiempo que desquicia el tiempo y lo pone fuera de sus goznes ("out of joint"), en la anacronía y el contratiempo". ${ }^{28}$

Una decisión no totalitaria se toma desde una razón no sistemática ni sistémica. Una razón más allá del cálculo, que no coarta el deseo ni la promesa. Precisamente por la exigencia de una racionalidad incondicional e hipercrítica (esto es, crítica consigo misma, como un Estado de Derecho).

Sólo una razón que se quiere insuficiente proclama la firma y se hace de este modo responsable. Una razón insuficiente es todo menos irresponsable: acepta la responsabilidad hasta comprometerse a sí misma, hasta comprometer su propia razón y dar razón de sí, y se abre de este modo a la argumentación y la perfectibilidad. Sólo es responsable una razón insuficiente. Solamente una razón insuficiente pide seguir razonando.

$\mathrm{X}$.

Séptimo principio: trasladar el marco, la mundialización.

Dice Derrida: "La ausencia de horizonte es la condición del acontecimiento" 29 . Dice Julián Santos comentando a Derrida: "El mecanismo de enfoque es siempre un sistema de marcos, de parerga" ${ }^{\text {"30 }}$. Hay siempre más de un marco, más de un horizonte. Pero el principio de comodidad se ciega, de un lado, y la prepotencia de la lectura establecida no admite límites.

\footnotetext{
${ }^{28}$ Idem. Adiós. Trad. de Santos. Madrid: Trotta, 1998.

29 DERRIDA, J. Palabra. Trad. de Peretti y Vidarte. Madrid: Trotta, 2001, p. 40.

${ }^{30}$ SANTOS, J. Círculos viciosos, op. cit., p. 61. 
El poder calculador, el poder previsor y neutralizante, si no castrante o frustrante, es la prepotencia de la globalización: la aniquilación de cualquier acontecimiento, de cualquier transgresión, el poder fagocitador del neoliberalismo triunfante, la conjuración de la amenaza estética (porque una obra y una firma no dejarán nunca de amenazar), el conjuro de cualquier obra artística o de cualquier decisión.

Globalizar significa hoy hacerlo todo previsible, integrado a priori en la axiomática del capitalismo, no por supresión de cualquier marco, de cualquier parergon o contexto, sino por imposición de un único marco, el de la democracia liberal y el mercado expansivo que digieren cualquier alternativa, ese mercado en que se neutralizan las decisiones políticas o que quiere actuar como referente último de la valoración estética.

Esa globalización, esa falsa aldea global, cierra el círculo y pretende detener el sentido errante poniéndolo a circular por autopistas que desembocan en su propio inicio o que se dispersan al infinito haciendo equivalente cada uno de sus lugares; se superpone a la diseminación dibujando autopistas por las que navegar rápido para llegar siempre a lo mismo, a la misma meta; impidiendo, pues, el rodeo, la errancia por otros caminos, el desvío del sentido, el cambio de sentido que siempre ha provocado cada metáfora, el detenimiento o la pausa en cada lugar distinto.

La errancia del sentido en el texto, la incompletitud del texto, quedan sustituidas de nuevo por el sistema, el más omniabarcante y prepotente de los sistemas, el más ideologizado e imperialista de los sistemas: el del pensamiento único y el de la aniquilación de la transgresión, el de la reducción de cualquier valor ético o político o estético a valor de cambio.

Hagamos, pues, justicia a la mundialización. Al cuadro. En el cuadro, o fuera de cuadro, desencuadrados. Encuadrar lo político es preverlo, neutralizarlo. Encuadrar lo estético es conjurarlo. Abramos la puerta al espectro; es, quizá, lo justo. Y desapropiemos ${ }^{31}$. Revaluemos la impertinencia y

\footnotetext{
31 "El proceso de propiación organiza la totalidad del proceso del lenguaje o de intercambio simbólico en general, comprendidos todos los enunciados ontológicos. La historia (de la) verdad (es) un proceso de propiación. Lo propio no depende, pues, de una interrogación onto-fenomenológico o semánticohermenéutica. La pregunta del sentido o de la verdad del ser no es susceptible de la pregunta de lo propio, del intercambio indecidible de mayor a menor, del dar-tomar, del dar-guardar, del dar-dañar, del golpe de don. No es susceptible porque se encuentra inscrita en él. Cada vez que surge la pregunta de lo propio en los campos de la economía (en sentido restringido), de la lingüística, de la retórica, del 
la no pertenencia, desestabilicemos, apostemos, pues, por un arte impertinente, por una política impertinente e inconveniente con respecto al orden dado, indecidible, urgente, por un juicio o una decisión inconmensurables.

Busquemos la desregulación de lo estético o de lo político (otro nombre de la libertad, o de la autonomía). No la desregulación económica. La deconstrucción no proporciona un programa ni estético ni político, por supuesto: no dice a nadie lo que tiene que hacer. Pero no soporta cualquier programa.

Desjerarquicemos: otra forma de anarquía: "Por consiguiente, tanto en el terreno político como en el terreno de la traducción poética o filosófica, el acontecimiento que hay que inventar es un acontecimiento de traducción. No de traducción en la homogeneidad unívoca, sino en el encuentro de idiomas que concuerdan, que se aceptan sin renunciar en la mayor medida posible a su singularidad. En todo momento se trata de una elección difícil". ${ }^{32}$

\section{XI.}

Octavo: hacer justicia. Principio de no indiferencia.

Hay en la deconstrucción un pensamiento de la transcendencia; más allá de toda metafísica tradicional, sin embargo. Inmanencia y transcendencia constituyen un límite que siempre queda por desplazar. El sentido no es inmanente ni transcendente; se escapa entre los dedos (es quizá su carácter trágico, según la lectura nietzscheana), como, en una herida que sangra, sangre exterior porque es interior.

No se trata de una transcendencia coherente y dibujada sin mácula. Se trata de la obligación de no reconocer inmanencia alguna, en ese juego de remisiones sin fondo que cada huella nos solicita. En esta línea, los transcendentales derridianos - la justicia, la hospitalidad infinita...- son siempre más y menos que lo dado o lo exigido: otra cosa que las ideas regulativas kantianas, pues, a diferencia de éstas, su contorno nunca será recorrible, asimilable. Tampoco, por tanto, horizontes. Promesas insaturadas, exigencias

psicoanálisis, de la política, etc., la forma onto-hermenéutica de la interrogación muestra su límite" (DERRIDA, J. Espolones, op. cit., p. 74).

${ }^{32}$ DERRIDA, J. Palabra, op. cit., p. 56. 
espectrales que entran dentro del cuerpo configurando el deseo y sin dejarse definir, que hacen de lo imposible lo más vívido y lo más vivido.

Exigencias imposibles: "Este im-posible no es privativo. No es lo inaccesible, no es lo que yo puedo remitir indefinidamente: se anuncia a mí, cae sobre mí, me precede y me sobrecoge aquí y abora, de una manera no virtualizable, en acto y no en potencia. Viene sobre mí desde arriba, bajo la forma de una inyunción que no espera en el horizonte, que yo no veo venir, que no me deja en paz, ni me autoriza nunca a remitir a más adelante. Esta urgencia no se deja idealizar, como tampoco se deja el otro en cuanto que otro. Este im-posible no es pues una idea (reguladora) ni un ideal (regulador). Es lo más innegablemente real que hay. Lo mismo que el otro. Lo mismo que la différance irreductible y no reapropiable del otro". 33

Desquiciando el tiempo, la paciencia y desmontando la posibilidad de cualquier conciencia satisfecha, introducen el desasosiego en el cuerpo mismo, imposibilitan el presente y la presencia, y hacen ingenua la plenitud de cualquier experiencia a la vez que exigen que haya alguna. Introducen en el cuerpo mismo la quiebra de la representación (de la mímesis, de la copia, pero también de la cesión de voluntades), dando fuerza al deseo y a la noindiferencia, invitando a la escritura sin pausa.

Nos citan, pues.

La sangre transcendente, la sangre que corre hacia afuera a partir de la herida interior (quiebra, ruptura, desajuste orgánico o estructural interno), pide justicia. Hay que hacer justicia, precisamente porque no sabemos nunca muy bien lo que esta exigencia demanda.

Llamamos no-indiferencia a la doble actitud que,por una parte, impide la clausura de la interpretación, se sabe vulnerable a la alteridad, se compromete con la promesa, y, por otro lado, desaloja cualquier buena conciencia ${ }^{34}$, cualquier satisfacción. Ninguna obra de arte, ningún juicio estético, ninguna

\footnotetext{
${ }^{33}$ Idem. Canallas, op. cit., p. 108.

34 "Es que hay que evitar a toda costa la buena conciencia. No sólo la buena conciencia como mueca de una vulgaridad complaciente, sino simplemente la forma segura de la conciencia de sí: la buena conciencia como certeza subjetiva es incompatible con el riesgo absoluto al que debe exponerse toda apuesta, todo compromiso, toda decisión responsable - si es que la hay" (DERRIDA, J. Aporías, op. cit., p. 40).
} 
decisión política será satisfactoria ni borrará la exigencia de justicia, ni borrará la incomodidad. La deuda es infinita para un ser mortal ${ }^{35}$.

Cierto: todo es interpretación, Dios ha muerto. Pero hay siempre más de una. Ninguna es justa. Y por eso la petición de justicia no cesa. Hay que ir ajustándose y ajustándolas. -

Hacer justicia es responder a la promesa del sentido, seguir prometiendo, exigiendo, com-prometer, prometer juntos desde una comunidad dislocada.

Hacer justicia: renunciar a neutralizar el acontecimiento, a archivarlo, dejarse sorprender, abrir tiempo, dar tiempo al tiempo y hacer sitio, respetar (sí, respetar) el secreto, el resto, la ceniza, la firma, hacer de la memoria un deber. Aceptar lo imposible como imposible. Hacer lo imposible, políticamente, artísticamente; no consumirlo, no consumarlo. No reducir lo desajustado.

Desajustado o todavía no justo. Una especie de belleza: Porque "hablamos de belleza cuando nos enfrentamos a algo que es a la vez deseable e inaccesible, algo que me habla, que me llama, pero que al mismo tiempo me está diciendo que es inalcanzable. Entonces puedo decir que es bello, que existe más allá, que tiene un efecto de transcendencia, que es inaccesible. Por consiguiente, que yo no puedo consumirlo: no es consumible, es una obra de arte. Esto es lo que define a la obra de arte: no ser consumible. Lo bello es algo que despierta mi deseo al decir precisamente "no me consumirás". Por ello, toda obra de arte es una obra de duelo gozosa, incluso aunque no haya ni obra ni luto", 36

RAMPÉREZ, Fernando. Postulados inciertos para una praxis estético-política deconstructiva. Trans/Form/Ação, (Marília); v.34, p.181-208, 2011, Edição Especial 2.

\footnotetext{
35 "Nos sentimos, pues, es verdad, llamados „en directo“ a respuestas o responsabilidades inmediatas. Es verdad también que éstas parecen inscribirse más naturalmente en el espacio de la filosofía política. Es verdad, siempre será verdad, y a este respecto estaremos siempre en falta. Nuestras respuestas y nuestras responsabilidades no serán jamás adecuadas ni jamás suficientemente directas. La deuda es infinita. Urgente, puesto que infinita. A priori infinita para un ser finito, desde el momento en que un deber, si lo hay, se le presenta" (DERRIDA, J. Políticas de la amistad, op. cit., p. 97).

${ }^{36}$ DERRIDA, J. No escribo sin luz artificial. Trad. de Ibañes y Pozo.Valladolid: Cuatro, 1999, p. 170. 
ABSTRACT : Deconstruction, precisely because it doesn't prescribe neither an aesthetics nor a policy, acts as an aperture strategy to/of the different and the alterity, producing in this way a nomadic proposal about thinking and action. Several categories that have focused the reflection in aesthetics and in politics for centuries, such as representation, judgment, interpretation, sense, signature, secret, etc, they met their own powerlessness or their dark side or just a new "inappropriate" reading trough a deconstructive analysis. This analysis contributes to think otherwise an aesthetics and a politics to come.

KEYWORDS: Deconstruction. Aesthetics. Policy. Interpretation. Sens. 